\title{
Activity of domain walls of epitaxial ferrite-garnet films caused by external electric fields
}

\author{
V.E.Koronovskyy, Y.A.Vakyla \\ Department of Radiophysics, Electronics and Computer Systems, \\ T.Shevchenko Kyiv National University, \\ 4-g Glushkova Ave., 03127 Kyiv, Ukraine
}

Received July 7, 2015

\begin{abstract}
Sensitivity of domain walls of epitaxial films of ferrite garnets to applying of external constant and variable electric fields under two different experimental conditions was investigated with use of optical polarimetry method. It is shown that "activity" of domain walls increases in the vicinity of areas with non-uniform induced magnetic anisotropy caused by external spatially non-uniform electric field.
\end{abstract}

Keywords:magneto-electric effect, electric field, domain wall, domain structure.

Чувствительность доменных границ эпитаксиальных пленок ферритовых гранатов к подключению внешних постоянного и переменного электрических полей при двух разных экспериментальных условиях исследовалась с использованием метода оптической поляриметрии. Показано, что "активность" доменных границ пленок возрастает в окрестности областей с неоднородной наведенной магнитной анизотропией, индуцированной внешним пространственно неоднородным электрическим полем.

Прояви активності доменних меж епітаксійних плівок феррит-гранатів у зовнішніх електричних полях В.Є. Короновсъкий, Ю.О. Вакула

Чутливість доменних меж епітаксійних плівок феритових гранатів до підключення зовнішніх постійного та змінного електричних полів для двох різних експериментальних умов досліджувалася з використанням методу оптичної поляриметрії. Показано, що "активність" доменних меж плівок зростає в околі ділянок з неоднорідною наведеною магнітною анізотропією, індукованою зовнішнім, просторово неоднорідним електричним полем.

\section{Introduction}

Yttrium-iron-garnets (YIG) are wellknown non-homogeneous magnetic structures that are widely used as a subject of intense experimental and theoretical investigations throughout many years [1-4]. Thin YIG films grown by liquid phase epitaxy as materials with mixed anisotropy are using often as a modelling object for researches of magnetic and magneto-optical characteristics of magnetic insulators because there is a possibility for direct visual observations of ongoing processes due to the magneto-optical Faraday effect. Special interest is focused on YIG domain structure (DS) and their micromagnetic structural elements - the domain walls (DW). The DS of YIG consists of periodically alternating small areas with antiparallel magnetization direction, separated by a nonuniform magnetic microstructures - the DWs, in which the direction of spins orientation is changing at transition from one domain to another. Nowadays there are also publications about manifestations of magneto-electric (ME) effect (MEE) in YIG single crystals 
and epitaxial YIG films [5-9]. Investigations of behavior of YIG micromagnetic structural elements in external electric fields ( $E$-fields) provoke the particular interest nowadays. An idea to create the $\mathrm{ME}$ devices where the magnetic characteristics are controlled by electric field and/or the electric characteristics are controlled by magnetic field - looks as a very attractive subject for applications, and interest to these phenomena are very active currently because of potential applications to devices [10]. It is possible to consider some examples for applications of $\mathrm{ME}$ materials nowadays: devices for modulation of amplitudes, polarizations and phases of optical waves, ME data storage and switching, optical diodes and others.

It was already informed by us about results of investigations of the MEE displays both on multi-domain sites of ferrite garnets and on small areas of separate domains [11-14]. Spatially homogeneous, variable low-frequency electric field was applied to the researched sample in these investigations.

Investigation of reaction of YIG micromagnetic non-homogeneities to inclusion of external electric field is the goal of the given paper. Thus, the behavior of specified structural elements of YIG (in particular the DWs) interested us in spatially homogeneous and non-homogeneous electric fields for carrying out the comparative analysis. Besides, reaction of YIG DS to applied of the additional channel of external influence - constant $E$ field $\left(E_{(-)}\right)$jointly with variable $E$-field $\left(E_{(\sim)}\right)$ and separately, was interesting to us.

\section{Experimental}

For realization of the specified tasks, we used highly sensitive technique of optical polarimetry (detailed description of our setup can be found in [11]). This method allows us to measure the change of light polarization plane rotation in external $E$-field. Authors of [7] named this effect as electromagneto-optical effect (EMOE). In our setup the investigated YIG film was placed between two optically transparent electrodes and electric field was applied to them. The electrodes were deposited on the thin glass plates. For the fixed value of $E$-field frequency and for several values of amplitude of the $E$-field, we measured the change of light polarization plane rotation in the external $E$-field $\left(\alpha_{\mathrm{EMO}}\right)$. He-Ne laser $(\lambda=$ $0.63 \mu \mathrm{m}$ ) was used in our experiments.
But considering problem which is discussed in the given article, we have essentially changed the conditions of our experiments carrying out in comparison with described ones in [11]. In particular, one of optically transparent electrodes, we have made not habitual, rectangular form (with sizes exceeding the sizes of the sample as it was in our early experiments) but in the form of small triangle with one of the angles, especially sharp. Geometrics of the electrode-triangle were less from sizes of the sample. The sample (its substrate) has been placed on a rectangular electrode. The electrode-triangle was over the film's surface and could be displaced (at requirement) concerning the film surface. Choice of such geometry of electrodes allows us to carry out researches as in homogeneous $E$-field (the central area of an electrode-triangle) and in non-uniform (a point under the sharp angle of triangle). Thus, the area of laser scanning on the sample was fixed and the top electrode was twice exposed by appropriate amount, considering described above. The sharp angle of the electrode-triangle (local area of the non-uniform $E$-field) could be placed over that or other site of DS, in particular over DW and that interested us first of all. Use of round diaphragm in our experiments allowed us to allocate the sites of the film of about $4 \mu \mathrm{m}$ in diameter. The investigated YIG films with typical labyrinth structure were deposited on the $\mathrm{Gd}_{3} \mathrm{Ga}_{5} \mathrm{O}_{12}$ substrates with thickness of about $580 \mu \mathrm{m}$. The typical thickness of the films was about $12 \mu \mathrm{m}$, the width of domains was about $14 \mu \mathrm{m}$ at $H=0$, and the DW width was about $0.4 \mu \mathrm{m}$. The domain's magnetization was normal to the film plane.

\section{Results and discussion}

Fig. 1 shows results of measuring changes of light polarization plane rotation in electric field at local, fixed with laser beam, area of DS $(\varnothing \approx 5 \mu \mathrm{m})$, allocated by diaphragm. Measurements were conducted at frequency of alternating electric field $(800 \mathrm{~Hz})$. The indicated area of laser scanning was chosen so that to be exposed to local segment of direct (flat) area of the DW. Moreover, the selected segment of the DW should initially be in the middle of stated local zone being under control due to the alteration of value for magneto-optical signal (at zero value of $E$-field). The magneto-optical signal shall be equal to zero in case of the DW is located directly in the 


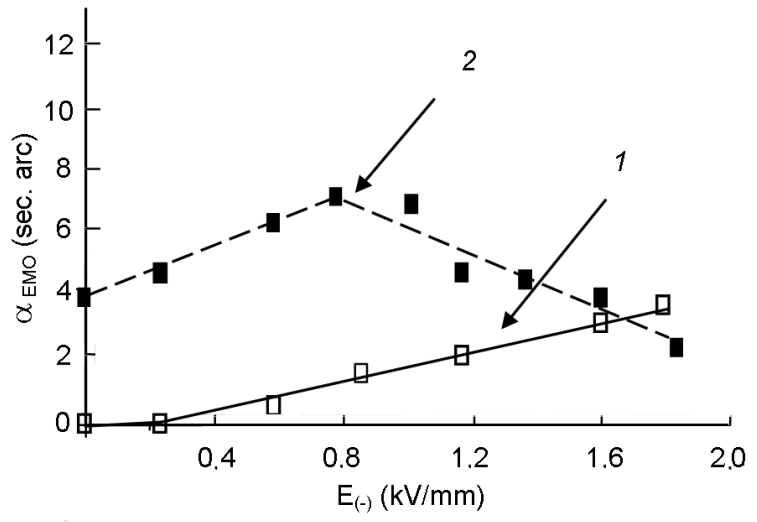

Fig. 1. Electric-field dependences of $\alpha_{\mathrm{EMO}}$ for local site of YIG film with DW in investigated area, when $E_{(\sim)}=2.8 \mathrm{kV} / \mathrm{mm}$. 1 - for spatially homogeneous $E$-field; 2 - for not spatially homogeneous $E$-field.

middle of scanning zone, because when transfer from domain with one direction of magnetisation to near domain with opposite direction, the magneto-optical signal reverses its sign. I.e. in the case if the DW is in the middle of researched area, the magneto-optical signal from adjacent domains cancels out.

Curve 1 in Fig. 1 shows nature of change for the magneto-optical signal when attaching external constant $E$-field $\left(E_{(-)}\right)$, at fixed value of alternating $E$-field $\left(E_{(\sim)}\right)$. Top electrode is herewith oriented such a way that its central (wide) part covered completely and evenly the area for laser scanning. I.e. in this case the investigated local area of DS is in spatially homogeneous electric field. As it is shown in the graphic, the magnetoelectric signal at specified experimental conditions is revealed only under common action of constant and the alternating electric fields and varies linearly with increase of constant $E$-field.

When changing the experimental conditions by shifting top electrode and directing its sharp end over the area of laser scanning, spotted higher, we observed absolutely different electric field behavior. Thus, even at zero value of constant $E$-field, magnetoelectric signal was registered (curve 2 on Fig. 1). With increase of the constant $E$-field, value of $\alpha_{\text {EMO }}$ goes up as in the previous case. But when reaching certain value of the constant $E$-field ( $0.7 \mathrm{kV} / \mathrm{mm})$, character of behavior is changing and the value of $\alpha_{\text {EMO }}$ starts decreasing with increase of the constant $E$-field, which was not observed in the homogeneous $E$-field.
To our point of view the indicated differences in presented electric-field behaviors can be explained in the following way. In the first case (curve 1) alternating $E$-field causes rotation of the light polarization plane in each of domains [11]. Because $\alpha_{\text {EMO }}$ value was close to zero, it appears that DW did not shift from its initial position in the area for laser scanning. Applying the constant electric field causes the occurrence of EMO signal (when reaching certain value of $E$-field) at frequency of alternating $E$-field. Alteration (increase) of the effect when the constant $E$-field is increasing may be explained by small shift of the DW from its initial position or unidirectional broadening of the wall to the area of one of the domains.

In the second case (curve 2) the $E$-field in the area of laser scanning is not spatially homogeneous. Initially, the part of only one of two domains being exposed to the zone of laser "spot" is covered with acute-angled part of top electrode. This explains the presence of EMO signal in the alternating $E$-field. This is effect from local part of the domain of one sign (namely direction of magnetisation). Applying the constant $E$-field predictably causes increase of the effect value. But when reaching the certain value of field, it is possible to observe sharp decrease of the effect value that was not observed when analyzing homogeneous field. In our opinion, the indicated peculiarity may have the following explanation. Acuteangled part of the top electrode was exposed such that sharp end was directly above the part of DW and did not "touch" the adjacent domain (of opposite sign) in the area of laser scanning. I.e., as it was mentioned, we initially register the impact of alternating and constant electric fields to the area of one domain, limited by the DW on one side. However, discontinuity of electric field causes the effect that in the point below the sharp end of top electrode its maximum values will be reached. These values sufficient to actuate (shift or extend slightly) the DW, or, if to be exact, its local area within sharp part of electrode. Such reaction of the DW to $E$-fields, possibly, leads to the fact that the small local site of the next domain of other sign will get to the area of laser scanning and will lead to corresponding decrease of value of registered effect.

Thus, it is possible to believe, that main cause for the described reaction of the DW can be the occurrence in external $E$-field under sharp edge of the top electrode the 


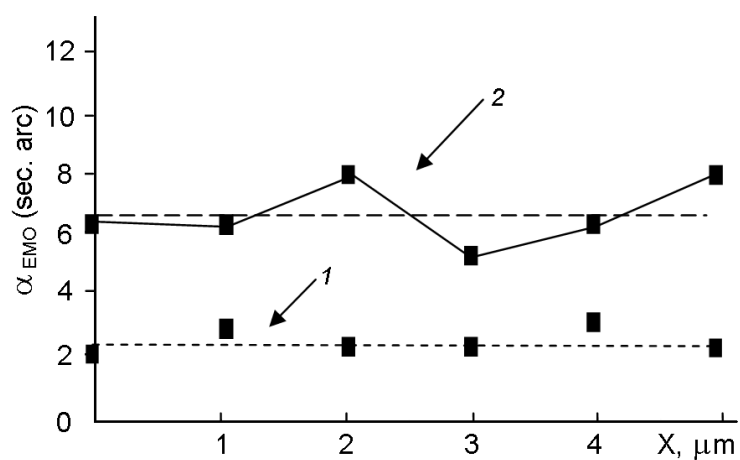

Fig. 2. Dependences of $\alpha_{\text {EMO }}$ parameter from position of scanning diaphragm in the straight area of DW at $E_{(\sim)}=3.5 \mathrm{kV} / \mathrm{mm}$ and $E_{(-)}=2.5 \mathrm{kV} / \mathrm{mm}:(1)-$ dependence for spatially homogeneous field; (2) - dependence for not spatially homogeneous field.

local area with inhomogeneous induced magnetic anisotropy in YIG film. Including fact that DWs in thin epitaxial films of iron garnets are very sensitive to the tiniest changes of magnetic anisotropy [11], their reaction to local inhomogeneous of electric field in the above mentioned testing conditions becomes obvious (Fig. 1, curve 2). Herewith it is possible the occurrence of local transformations in DW making impact to registered effect, however, it is only hypothetical because our setup does not allow to investigate the DW separately from the domain block. Our assumption about determinative role of anisotropy changes corresponds to the guess in $[15,16]$ about anisotropy change in YIG under electric field influence.

Fig. 2 (curve 1) shows the results of measuring of $\alpha_{\mathrm{EMO}}$ when we are scanning by laser beam along the straight area of the DW at $E_{(\sim)} \neq 0$ and $E_{(-)} \neq 0$. Diameter of diaphragm revealed area of the DS comprises approximately $10 \mu \mathrm{m}$ and is evenly covered with the central part of the top electrode. Conditions for orienting laser "spot" are the same as in the previous case. As we see from the graph, the registered signal does not change practically. Fig. 2 (curve 2) shows results of the indicated scanning, but on condition that end of sharp angle of the top electrode will be every time oriented over the DW. As we see from the graph, the EMO signal changes chaotically when transferring between spots, though significant "discharges" are not revealed. Instability of $\alpha_{\text {EMO }}$ is caused by complexity of exact orientation for the electrode edge over the DW when transferring between spots. Though by means of

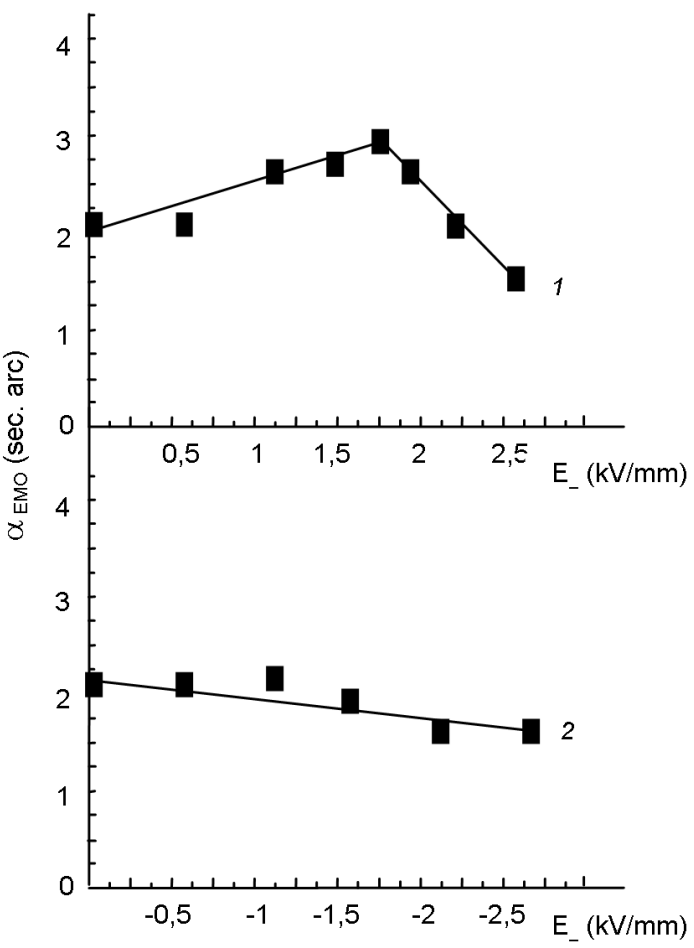

Fig. 3. Electric-field dependences of $\alpha_{\text {EMO }}$ parameter, measured on local area of separate domain without DW on the site of laser probing. Presented results for two polarities of static electric field (see curve 1 and 2 ) and at fixed value of alternating field $\left(E_{(\sim)}=\right.$ $3.5 \mathrm{kV} / \mathrm{mm})$.

averaging value for registered signal, as we see, significant abnormalities as in the case of homogeneous $E$-field were not revealed.

The results shown in Fig. 1 and Fig. 2 are related to the local areas of the DS containing the DW. Fig. 3 shows the results of measuring $\alpha_{\text {EMO }}$ value in the local area of the separate domain without DW on the site of laser "spot" (diameter of approximately $8 \mu \mathrm{m})$. However, the researched area of domain was picked out so that the DW was at the joint with scanned area. I.e. laser beam in this case "caught" the wall area of domain but did not cover the DW itself. The investigated area was evenly covered with the central part of the top electrode, i.e. measurements were conducted in homogeneous electric field. Such choice of experimental conditions is determined by the above described (Fig. 1, curve 2) "activity" of the DW at common applying of alternating and constant electric fields. There is necessity to check this magnetoelectric "activity" in details. 
In this case we measured the electricfield dependences at two polarities of static electric field (curve 1 and curve 2 of Fig. 3 ) and at fixed value of the alternating field. As we can see from dependences, alternating $E$-field causes changing of the angle of the light polarization Faraday plane rotation on investigated area of the domain. Applying static electric field on one hand (curve 1), initially causes the increase in value of $\alpha_{\mathrm{EMO}}$ in the interval of field alteration from 0 to $\sim 2 \mathrm{kV} / \mathrm{mm}$. But in the further increase of field we observe smooth decrease of the signal. When changing the polarity of static $E$-field (curve 2 of Fig. 3), its impact to the value of $\alpha_{\mathrm{EMO}}$ starts revealing slightly from the value of $1.3 \mathrm{kV} / \mathrm{mm}$. Starting from the indicated value of field the value of effect decreases insignificantly. Thus, we see that the discussed effect in the magnetic domain is sensitive to polarity of constant $E$-field. In our opinion the area of decreasing of the effect in curve 1 is caused by "tightening" of DW into the area of laser scanning by the $E$ field. It is necessary to remind that initially we chose the local area of domain for investigation so that the DW was directly on a joint with the scanning site. I.e. even under indicated experimental conditions the DW reveals "activity" (though weak), related to the ME effect.

\section{Conclusion}

Thus, results of our experiments show sensitivity (but weak) of domain walls of ferrite-garnets epitaxial films to the combined influence of variable and constant electric fields. It is revealed, that the mentioned sensitivity increases in the vicinity of areas with the non-uniform induced magnetic anisotropy caused by external spatially non-uniform electric field.

\section{References}

1. J.F.Dillon, J. Appl. Phys., 29, 539 (1958).

2. L.E.Helseth, R.W.Hansen, E.I.Il'yashenko et al., Phys. Rev. B, 64, 174406 (2001).

3. B.K.Ostafiychuk, V.D.Fedoriv, I.P.Yaremiy et al., Phys. Status Solidi A, 208, 2108 (2011).

4. M.Chetkin, Y.N.Kurbatova, T.Shapaeva, Functional Materials, 17, 205 (2010).

5. T.H.O'Dell, Phil. Mag., 6, 487 (1967).

6. G.Aubert, J. Magn. Magn. Mater., 31, 767 (1983).

7. B.B.Krichevtsov, R.V.Pisarev, A.G.Selitskij, Zh. Eksper. Teor. Fiz. Pis'ma, 41, 317 (1985).

8. A.S.Logginov, G.A.Meshkov, A.V.Nikolaev, A.P.Pyatakov, Zh. Eksper. Teor. Fiz. Pis'ma, 86, 115 (2007).

9. Z.V.Gareeva, R.A.Doroshenko, F.A.Mazhitova, N.V.Shulga, J.Magn.Magn.Mater., 385, 60 (2015).

10. M.Fiebig, J.Phys. D: Appl. Phys., 38, 123 (2005).

11. V.E.Koronovskyy, S.M.Ryabchenko, V.F.Kovalenko, Phys. Rev. B, 71, 172402 (2005).

12. V.E.Koronovskyy, Functional Materials, 13, 515 (2006).

13. V.E.Koronovskyy, Appl.Phys.A, 95, 351 (2009).

14. V.E.Koronovskyy, N.D.Gorchinskiy, Functional Materials, 18, 37 (2011).

15. G.Velleaud, B.Sangare, M.Mercier, G.Aubert, Solid State Commun., 52, 71 (1984).

16. A.F.Kabychenkov, F.V.Lisovskii, E.G.Mansvetova, Zh. Eksper. Teor. Fiz. Pis'ma, 97, 265 (2013). 